\title{
0 estatuto da concepção nietzschiana de mundo
}

\author{
The mode of Nietzsche's conception of the world
}

\author{
Eder Corbanezi \\ Universidade de São Paulo
}

\section{RESUMO}

Nietzsche confere à sua concepção de mundo como vontade de potência o estatuto de interpretação, hipótese e ensaio. Procuraremos mostrar que, com isso, ele sublinha seu perspectivismo e antidogmatismo, mas ao mesmo tempo reivindica a necessidade e a superioridade de sua teoria: de um lado, ela resultaria de uma boa arte de interpretação e, de outro, seria afirmável apenas por formas de vida fortes e superiores. A nosso ver, porém, tal posição suscita três possíveis dificuldades, que analisaremos da seguinte maneira: primeiro, investigaremos a possibilidade de uma distinção absoluta entre artes boas e ruins de interpretação; em seguida, buscaremos compreender por que Nietzsche considera necessária a formulação de sua concepção de mundo, derivando-a não só de premissas por ele subscritas, mas também da crença na causalidade, criticada em boa parte de seus textos; por fim, examinaremos uma possível circularidade nos argumentos de que, segundo nos parece, o filósofo se vale para reclamar a superioridade de sua visão de mundo.

\section{PALAVRAS-CHAVE}

Mundo; Vontade de potência; Interpretação; Hipótese.

\begin{abstract}
Nietzsche presents his conception of the world as will to power as an interpretation, a hypothesis, and an essay. We will attempt to show that in this way he underlines his perspectivism and antidogmatism, but at the same time he claims the necessity and the superiority of his theory: on the one hand, it would result from a good mode of interpretation and, on the other hand, it would be affirmable by stronger and superior types of life. However, we think this position is susceptible of containing three possible difficulties, which we will analyze as follows: first of all, we will investigate the possibility of an absolute distinction between good and bad modes of interpretation; next, we will try to understand why Nietzsche considers the formulation of his conception of the world as a necessary one, even though he derives it not only from premises he subscribes to, but also from the belief in causality, which he often criticizes; finally, we will examine a possible circularity in the arguments we consider the philosopher uses in order to claim the superiority of his view of the world.
\end{abstract}

\section{KEY WORDS}

World; Will to Power; Interpretation; Hypothesis. 
Ao apresentar a sua concepção de mundo como vontade de potência, Nietzsche a ela se refere como uma interpretação, uma hipótese e um ensaio. Desse modo, ele dá a ver o caráter perspectivístico e antidogmático que a anima, oferecendo assim indicações sobre o seu estatuto. Este, contudo, revela-se mais complexo do que poderia parecer à primeira vista. Se o autor de Zaratustra confere à mencionada concepção de mundo uma dimensão interpretativa, ele não pretende, todavia, vê-la figurar como apenas mais uma interpretação entre outras, mas, ao contrário, reivindica a sua superioridade diante das demais; se a designa como hipótese e ensaio, tampouco quer sugerir com isso que ela resulte de uma elaboração arbitrária, mas, antes, de um procedimento a tal ponto rigoroso que a sua formulação se revela até mesmo necessária.

Assim, de maneira geral, esperamos mostrar que, ao caracterizar a sua concepção de mundo como interpretação, hipótese e ensaio, Nietzsche procura sublinhar o seu perspectivismo e antidogmatismo, sem por isso colocar-se na posição de um relativista radical que afirmaria a equivalência de todas as visões de mundo: além de hierarquizar as outras interpretações, ele considera a sua própria necessária e superior às demais. ${ }^{\mathrm{I}}$ É preciso, entretanto, esclarecer o caráter dessa necessidade e dessa superioridade, tanto mais por serem elas reivindicadas por uma filosofia que se propõe radicalmente perspectivística e antidogmática.

Com efeito, a posição de Nietzsche implica, a nosso ver, ao menos três possíveis dificuldades, que contamos examinar a seguir. Se o filósofo pleiteia a superioridade de sua concepção de mundo na medida em que ela resultaria de uma boa arte de interpretação, investigaremos, em primeiro lugar, a possibilidade — tendo em vista o seu próprio conceito de interpretação — de uma distinção absoluta entre artes interpretativas boas e ruins. Se o autor de Para além de Bem e Mal reivindica a necessidade da formulação de sua concepção de mundo como vontade de potência, buscaremos compreender, em seguida, por que essa incontornabilidade, tal como apresentada no parágrafo 36 do referido livro, decorre não apenas de premissas subscritas por Nietzsche, como seria de esperar, mas também de uma crença, a crença na causalidade, objeto de ampla crítica em sua obra. Se, por fim, a pretensa superioridade da concepção de mundo como vontade de potência se explica, entre outras razões, em virtude de ser ela afirmável por formas de vida consideradas por Nietzsche fortes e superiores, perguntaremos se tal posição encerra uma lógica circular e, em caso de resposta afirmativa, de que maneira a sua filosofia receberia semelhante caracterização, levando em conta o modo como ela própria, em nosso entender, concebe o problema da circularidade.

I A propósito do relativismo, cf. Lima, 20I0, e Itaparica, 20I0, pp. 239-253. 


\section{Boas e más artes de interpretação: uma distinção possivel?}

Nietzsche procede de modo coerente com a sua concepção de mundo como vontade de potência ao atribuir-lhe um estatuto interpretativo. De um lado, o filósofo apresenta seu pensamento da "vontade de potência" como "ensaio de uma nova interpretação de todo acontecer" ; de outro, ele afirma "o caráter interpretativo

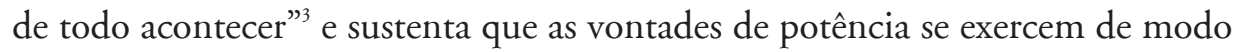
interpretante: "A vontade de potência interpreta". ${ }^{4}$ Assim, o estatuto da doutrina concorda com o seu conteúdo; mais do que isso: o conteúdo da doutrina deter-

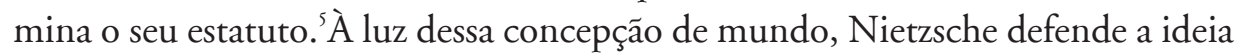
de que mesmo as pretensas verdades absolutas e explicações de mundo não são senão interpretaçôes ${ }^{6}$, as quais resultam de diferentes configuraçôes de vontades de potência. Hierarquizando as interpretações, o filósofo mostra, porém, que não as toma como equivalentes. Assim procede ele, por exemplo, no parágrafo I4 de Para além de Bem e Mal. Ali, afirma que a física é "apenas uma interpretação e uma disposição do mundo [...] e não uma explicação do mundo". No entanto, adverte que, para a sua época, "ela vale como mais, [...] como explicação". É que a física repousa na crença nos sentidos, tendo os olhos e os dedos a seu favor, e desse modo está em conformidade com o "sensualismo popular" que serve como o cânone de verdade numa época de gosto plebeu, para a qual o que "explica" é "o que se deixa ver e tocar". A física então fascina e persuade. ${ }^{7}$ Em oposição a

2 Fragmento Póstumo 39 [I] de agosto/setembro de I885, KSA II.6I9.

3 Fragmento Póstumo I [II5] do outono de I885/primavera de I886, KSA I2.38.

4 Fragmento Póstumo 2 [I48] do outono de I885/outono de I886, KSA I2.I39.

5 Sobre a presença das noções de perspectivismo e de interpretação na concepção nietzschiana de mundo como vontade de potência, cf. Marton, 2000, em particular pp. 22I-227; Müller-Lauter, 1974, em especial p. 43ss; Azeredo, 2008, pp. 45-IO2.

6 "Interpretação de mundo, não explicação de mundo", anota frequentemente o filósofo (por exemplo, no Fragmento Póstumo 42 [I] de agosto/setembro de I885, KSA II.69I, e no Fragmento Póstumo I [I2I] do outono de I885/primavera de I886, KSA I2.39). Ou ainda simplesmente: "Interpretação, não explicação" (ver os Fragmentos Póstumos 2 [78] do outono de I885/outono de I886, KSA I2.98, 2 [82] do outono de I885/outono de I886, KSA I2.IOO-IOI, e 5 [50] (30) do verão de I886/outono de I887, KSA I2.203). Em suas anotações, encontra-se também a fórmula: "Interpretação, não conhecimento" (Fragmentos Póstumos 2 [70] do outono de I885/outono de I886, KSA I2.92, e 2 [82] do outono de I885/outono de I886, KSA I2.IOI). Nessa direção, Nietzsche sustenta que o mundo não é passível de conhecimento, mas interpretável (Fragmento Póstumo 7 [60] do final de I886/primavera de I887, KSA I2.315). E à pergunta "o que, somente, pode ser conhecimento?", responde: “Interpretação', não 'explicação'” (Fragmento Póstumo 2 [86] do outono de I885/outono de I886, KSA I2.IO4). Em outros momentos, ele assegura que o que se toma muitas vezes por "explicação" consiste a rigor em "descrição" (por exemplo, em A gaia Ciência $\$$ II2, KSA 3.472).

7 Para além de Bem e Mal $\$$ I4, KSA 5.28. Sobre o sensualismo, cf. Nasser, 20I5, em particular 
esse "sensualismo popular", Nietzsche evoca o "modo platônico de pensar, que era um modo nobre de pensar", cujo "fascínio" repousa desta vez "na resistência contra a evidência dos sentidos". ${ }^{8}$ Embora considere o modo platônico de pensar superior, Nietzsche não o toma por isso como uma explicação de mundo, mas sim como uma "interpretação do mundo". ' Portanto, nem a filosofia dogmática, nesse caso representada por Platão, nem a ciência, exemplificada pela física, produzem explicações de mundo; elas dão origem somente a interpretaçôes de mundo. E a superioridade de uma determinada interpretação em relação a outra não a transforma, como se vê, numa explicação.

Nietzsche procede de modo semelhante ao conferir um estatuto interpretativo à sua própria concepção de mundo como vontade de potência. Apresentando-se como "velho filólogo", ele inclui a concepção de "legalidade da natureza" defendida pelos físicos entre as "artes-de-interpretação ruins": tal concepção, diz aos físicos, "só subsiste graças a vossa interpretação e 'filologia' ruim — não é nenhum fato, nenhum 'texto' ". ${ }^{10}$ Tomando a interpretação dos físicos como algo a ser, por seu turno, interpretado, Nietzsche afirma que ela constitui "somente um arranjo ingenuamente humanitário e uma distorção de sentido, com que dais [os físicos] plena satisfação aos instintos democráticos de alma moderna". "Para o filósofo, a tese da "legalidade da natureza" equivale a uma posição que quer ver "por toda parte igualdade diante da lei", donde a conclusão de que se trata de "um maneiroso pensamento oculto, em que mais uma vez está disfarçada a plebeia hostilidade contra tudo o que é privilegiado e senhor de si [...]" ${ }^{12}$ Em seguida, Nietzsche evoca a sua própria concepção de mundo como vontade de potência, introduzindo-a, no entanto, como o resultado de uma arte de interpretação oposta à dos físicos, isto é, como o produto de uma boa arte de interpretação. Ao atribuir um estatuto interpretativo à sua concepção de mundo, ele não a apresenta como uma explicação: nesse sentido, ela continuar a ser, portanto, "somente interpretação". ${ }^{13}$ Mas nem por isso o filósofo a entende como apenas mais uma interpretação, ou seja, como equivalente às demais. Ele avalia a sua, bem ao contrário, como superior às outras: e não apenas porque a reconhece

pp. $87-153$.

8 Para além de Bem e Mal $\$$ I4, KSA 5.28.

9 Ibid.

IO Para além de Bem e Mal $\$$ 22, KsA 5.37. Tradução de Rubens Rodrigues Torres Filho (Nietzsche, 2000), a partir de agora indicado como RRTF. Nessa passagem, a tradução foi modificada.

II Ibid.

I2 Ibid.

I3 Ibid. 
como uma interpretação, ao passo que os dogmáticos pretendem fazer com que as deles se passem por explicaçôes ou verdades absolutas, mas sobretudo porque a sua interpretação decorre, segundo ele, de uma boa arte de interpretação.

Com efeito, em certo sentido, o conceito de interpretação não significa um procedimento homogêneo. De modo geral, as interpretações se diferenciam conforme resultem de artes interpretativas boas ou ruins. É bem verdade que Nietzsche qualifica as interpretaçóes mais frequentemente de modo depreciativo do que elogioso: "exaltada e artificial" "in "infame" "15, "falsa"16 e "arbitrária" ${ }^{\text {"17 }}$ são alguns dos adjetivos empregados para desqualificar determinados modos de interpretar. Mas a depreciação de uma interpretação pode ocorrer de forma ainda mais específica: ao referir-se a uma "desavergonhada arbitrariedade da interpretação" ${ }^{\text {"18 }}$, por exemplo, o filósofo sugere que a própria caracterização de uma interpretação como "arbitrária" é suscetível de nuances, havendo desde arbitrariedades mais sutis até outras mais grosseiras, desde arbitrariedades involuntárias até outras planejadas, as quais configuram casos extremos, veementemente criticados por Nietzsche. De resto, em boa parte das ocasiōes em que menciona a arte de ler e de interpretar corretamente, trata-se justamente de apontar para a raridade desses casos e de incitar a um tal procedimento de leitura e interpretação. ${ }^{19}$ Desde o período em que era professor de filologia na Basileia, julgando que os filólogos haviam desaprendido a ler, Nietzsche já exortava: "Temos de aprender novamente a ler" ${ }^{20}$ Como não considerava os procedimentos de leitura equivalentes, insistia na necessidade de se adquirir um "método correto" de transmissão e de hermenêutica. ${ }^{21}$ Para o estabelecimento e a interpretação dos documentos escritos, que devem por fim visar a uma compreensão total da antiguidade, seriam imprescindíveis, entre outros requisitos, lógica rigorosa, conhecimento linguístico e sentido sutil para as possibilidades de corrupção do texto ${ }^{22}$ - sentido que Nietzsche continuará a exercitar, criticando tanto a corrupção de textos em sentido estrito (da Bíblia, por exemplo, corrompida pela Igreja, que introduz de maneira fraudulenta uma

I4 Humano, demasiado Humano I $\$$ I43, KSA 2.I39.

I5 Aurora $\$$ I3, KSA 3.26, tradução de RRTF.

I6 Fragmento Póstumo 34 [48] de abril/junho de I885, KSA II.435.

I7 Fragmento Póstumo I4 [I5I] da primavera de I888, KSA I3.333.

I8 Aurora $\$ 84$, KSA 3.79 .

I9 Cf. Fragmentos Póstumos 23 [22] do final de I876/verão de I877, KSA 8.4II, e 23 [Io8], do mesmo período, KSA 8.44I.

$20 \mathrm{KGW} \mathrm{II/3.373.} \mathrm{Trata-se} \mathrm{de} \mathrm{anotaçôes} \mathrm{para} \mathrm{o} \mathrm{curso} \mathrm{intitulado} \mathrm{Encyclopädie} \mathrm{der} \mathrm{klassischen}$ Philologie.

2 I Ibid., p. 388.

22 Ibid., p. 375. 
passagem a ser posteriormente utilizada em favor da profecia cristã) ${ }^{23}$ quanto a corrupção de textos em sentido amplo (tal como do "texto da natureza", preparado previamente pelos metafísicos para que se adapte à "explicação" que eles têm pronta de antemão). ${ }^{24}$ Se em seu curso de filologia Nietzsche já exigia "rigor moral" e preconizava uma leitura lenta e desconfiada, pondo à prova cada fato e cada passagem ${ }^{25}$, tais recomendações continuam a ecoar em textos posteriores, nos quais o filósofo exige o cultivo de uma boa arte de leitura e de interpretação: "Não se foi filólogo em vão, é-se ainda talvez, quer dizer, um professor da lenta leitura", escreve no último parágrafo do prefácio de Aurora. ${ }^{26}$ A filologia, prossegue ele, "ensina a ler bem, isto é, a ler lenta e profundamente, de modo atento e cuidadoso, com segundas intenções, deixando portas abertas, com dedos e olhos delicados". ${ }^{27}$ Assim, não é sem motivo que no parágrafo 22 de Para além de Bem e Mal Nietzsche se coloca na posição de um "velho filólogo", qualificado para apontar artes ruins de interpretação - entre as quais se encontra a concepção de "legalidade da natureza" dos físicos —, incapazes até mesmo de estabelecer fatos ou textos. Se no curso de introdução aos estudos de filologia clássica Nietzsche já mostrava que o estabelecimento de um texto ou de um fato depende de um rigoroso procedimento interpretativo, os conceitos de texto e de interpretação, como se vê, tornar-se-ão cada vez mais plurívocos e desempenharão papeis diversos no pensamento do filósofo; o que permanecerá sempre, contudo, será a exigência de uma boa arte de interpretação e de leitura, assim como, em contrapartida, a crítica às artes ruins.

É certo que Nietzsche continuará a servir-se dos conceitos de interpretação e de texto em seu sentido estrito, isto é, relacionados a documentos escritos: isso ocorre, por exemplo, nas ocasiōes em que exige uma leitura interpretativa de seus próprios textos $^{28}$ ou em que, como já vimos, critica o procedimento cristão de estabelecimento e de interpretação de textos, "arte de ler mal" caracterizada pela "improbidade" e pela "desavergonhada arbitrariedade da interpretação". ${ }^{29}$ Mas

23 Cf. Aurora $\$ 84$, KSA 3.80.

24 Cf. $O$ Andarilho e sua Sombra $\$$ I7, KSA 2.55I-552, tradução de RRTF.

25 Cf. KGW II, 3.375.

26 Aurora, "Prefácio", \$5, KSA 3.I7.

27 Ibid. Nietzsche designa a filologia, "em um sentido muito geral", como "a arte de ler bem" e de "poder decifrar fatos [...] sem falsificá-los com interpretação, sem perder, na exigência de compreensão, o cuidado, a paciência, a sutileza" (O Anticristo $\$$ 52, KSA 6.233). Sobre a filologia como a arte da lenta leitura, ver ainda o Fragmento Póstumo I9 [I] de outubro/ dezembro de I876, KSA 8.332. A respeito da arte de ler bem como filologia, cf. Silva, 2014.

28 Cf. Genealogia da Moral, "Prefácio", \$8, KSA 5.255-256.

29 Aurora $\$ 84$, KSA 3.79 . 
Nietzsche amplia consideravelmente o uso desses conceitos, a ponto de observar todo tipo de fenômeno como um texto a ser interpretado. É assim que o filósofo toma as disposições, inclinações e ações do santo como uma "escrita" que foi, no entanto, "falsamente interpretada", "segundo uma arte de interpretação tão exaltada e artificial quanto a pneumática interpretação da Bíblia" "; ; que designa a consciência como um "comentário mais ou menos fantástico sobre um texto desconhecido, talvez incognoscível" ${ }^{\text {"3i }}$; que se refere à Revolução Francesa como um texto que, todavia, desapareceu sob as interpretações daqueles que nele "por tanto tempo e de maneira tão apaixonada introduziram, por meio de interpretação, seus próprios entusiasmos e revoltas" ${ }^{\text {”2 }}$; que define a filologia, "em um sentido muito geral", como "a arte de ler bem" e de "poder decifrar fatos": sejam eles "livros, notícias de jornais, destinos ou fatos meteorológicos" ${ }^{33}$ Por fim, Nietzsche se referirá ao próprio mundo como um texto ou um fato a ser interpretado. ${ }^{34}$ As passagens em que Nietzsche trata da relação entre texto e interpretação dão margem, porém, a algumas dificuldades. De um lado, em uma série de escritos, ele defende a ideia de que não há fatos e, portanto, textos ${ }^{35} \mathrm{em}$ si mesmos, mas apenas como resultados de uma introdução prévia de sentido: "Não há nenhum 'fato em si', mas sim um sentido deve sempre primeiramente ser introduzido para que possa haver um fato".$^{36}$ Assim, a interpretação, entendida

30 Humano, demasiado Humano I $\$$ I43, KSA 2.I39.

3I Aurora $\$$ II9, KSA 3.II3.

32 Para além de Bem e Mal $\$ 38$, KsA 5.56.

33 O Anticristo $\$ 52$, KSA 6.233 .

34 Cf. Para além de Bem e Mal \$22, KSA 5.37. A propósito dessa extensão dos conceitos de texto e de interpretação, Müller-Lauter (I974, p. 44) indica que Nietzsche "utiliza com prazer a relação filológica texto-interpretação para o esclarecimento das relações fundamentais da efetividade”. Éric Blondel (I986, p. I45), por sua vez, sustenta que "Nietzsche estende os métodos da filologia" a tal ponto que a cultura e a realidade devem ser consideradas como textos a serem filologicamente interpretados (Ibid., p. 137). Também atribuindo um papel central a uma concepção mais ampla de filologia na filosofia de Nietzsche, Patrick Wotling (2009, p. 58) defende que, depois de criticar o conceito idealista de realidade, o pensador alemão estabelece "o texto da realidade-aparência", o qual se mostrará "legível como vontade de potência”.

35 Nas notas para o curso Enciclopédia da Filologia clássica, Nietzsche utiliza, entre outros, o termo Thatsache (KGW II, 3.375) como sinônimo de texto em sentido estrito, isto é, como documento escrito. Posteriormente, o mesmo vocábulo continuará a ser empregado, ao menos em algumas passagens, como sinônimo de texto não apenas em sentido estrito, mas também em sentido amplo, como é o caso do parágrafo 52 de $O$ Anticristo, citado pouco acima. O filósofo se vale igualmente da palavra Thatbestand como sinônimo de texto. No já mencionado parágrafo 22 de Para além de Bem e Mal, por exemplo, ele afirma que a concepção da "legalidade da natureza" dos físicos não é "nenhum fato [Thatbestand], nenhum 'texto'".

36 Fragmento Póstumo 2 [I49] do outono de I885/outono de I886, KSA I2.I4O. 
como processo de introdução de sentido ${ }^{37}$, não pode ser vista somente como um

37 A ideia de que interpretar significa antes introdução que extração de sentido pode ser depreendida, parece-nos, de vários escritos. "Não procurar o sentido nas coisas: mas introduzi-lo!", exclama o filósofo no Fragmento Póstumo 6 [I5] do verão de I886/primavera de I887, KSA I2.238. Em outra anotação (2 [82] do outono de I885/outono de I886, KSA I2.IOO), Nietzsche afirma: "Introduzir sentido [Sinn-hineinlegen] — na maioria dos casos uma nova interpretação sobre uma antiga interpretação tornada incompreensível, que agora é ela própria apenas um signo". A ideia de que, em vez de extrair, interpretar quer dizer introduzir sentido se faz notar no próprio modo como o filósofo se expressa, a saber, utilizando de maneira insistente o prefixo hinein, que veicula a noção de introdução, associado a diversas palavras, o que resulta em termos como, entre outros, hineininterpretirt, hineingedeutet, hineingelegt, hineingedichtet e sehen hinein. Além disso, o emprego do caso acusativo vem reforçar nessas situaçóes a referência ao movimento de introdução. Esse procedimento se verifica de modo exemplar no Fragmento Póstumo 9 [9I] do outono de I887, KSA I2.383-387, em que se lê: "A 'necessidade mecânica' não é um fato: nós, somente, a introduzimos por interpretação [hinein interpretirt] no acontecer" (Ibid., p. 383). Do mesmo modo, "nós introduzimos [hineingedeutet] sujeito[,] 'agente'[,] nas coisas" (Ibid., p. 383). E, "apenas conforme o modelo do sujeito, nós inventamos e introduzimos por interpretação [hineininterpretirt] a coisidade na confusão de sensações" (Ibid., p. 383). Adiante, escreve: "Verdade não é com isso algo que estivesse aí e algo que se pudesse encontrar, descobrir, - mas sim algo que se deve criar e que dá o nome para um processo, mais ainda, para uma vontade de dominação, que em si não tem nenhum fim: introduzir [hineinlegen] verdade, como um processus in infinitum, um ativo determinar, não um se tornar consciente de algo que fosse 'em si' fixo e determinado" (Ibid., p. 385). Em outro fragmento póstumo (I4 [I52] da primavera de I888, KSA I3.335), o filósofo afirma: "Acreditamos na vontade como causa até o ponto de, conforme nossa experiência pessoal em geral, introduzirmos [hineingelegt] uma causa no acontecer”. A ideia de introdução de sentido e de valor parece constituir intrinsecamente o conceito de interpretação, mesmo nos casos em que Nietzsche recorre aos termos Auslegung e auslegen, quer dizer, nos casos em que a palavra que designa o conceito de interpretação é composta com o prefixo aus, que contempla, entre outros, os sentidos de exteriorização e de extração. Se assim é, então não há uma pura extração, isenta de toda introdução de sentido: em outras palavras, todo auslegen é também um hineinlegen. No parágrafo 353 de A gaia Ciência (KsA 3.589), Nietzsche explora morfológica e semanticamente esses termos. Ali, depois de afirmar que a autêntica invenção dos fundadores de religião consiste em fixar uma espécie de vida e conferir-lhe uma interpretação [Interpretation], fazendo com que pareça possuir o mais elevado valor, exemplifica: "Jesus (ou Paulo), por exemplo, encontrou a vida da gente pequena numa província romana [...]: ele a interpretou, ele introduziu o mais elevado sentido e valor [er legte es aus, er legte den höchsten Sinn und Werth hinein] - e com isso a coragem para desprezar qualquer outra espécie de vida [...]”. A ideia de que todo auslegen consiste num hineinlegen está presente de modo explícito também num dos poemas acrescentados à segunda edição de $A$ gaia Ciência. Intitulado justamente Interpretation, o poema começa assim: "Leg ich mich aus, so leg ich mich hinein / Ich kann nicht selbst mein Interprete sein" (Scherz, List und Rache. Vorspiel in deutschen Reimen, 23, KSA 3.357). Para além desse caso específico — de identidade entre interpretador e interpretado, em que a introdução do interpretador no interpretado é mais patente o filósofo continuará a expor, com frequência em tom crítico, outras situações em que o intérprete se introduz no interpretado: aos olhos de Nietzsche, de acordo com uma passagem já mencionada, a Revolução Francesa aparece como um texto que desapareceu sob as interpretaçōes daqueles que nele "por tanto tempo e de maneira tão apaixonada introduziram, por meio de interpretação (hinein interpretirt), seus próprios entusiasmos e revoltas" (Para além de Bem e Mal \$ 38, KSA 5.56). Se interpretar consiste em introduzir sentido - isto é, se todo auslegen constitui um hineinlegen —, parece impossível que o 
procedimento posterior ao estabelecimento de um fato ou de um texto; antes, o próprio estabelecimento de fatos ou textos, em sentido estrito ou amplo, já constitui um procedimento interpretativo. Toda leitura, por conseguinte, tenha ela por objeto o estabelecimento de um texto ou um texto já estabelecido, consiste num procedimento interpretativo.

Por outro lado, diversos escritos de Nietzsche apontam, ao menos aparentemente, para outra direção: ao afirmarem que a boa arte de leitura é aquela que não falsifica o texto com interpretações, essas passagens sugerem uma separação entre texto e interpretação. Depois de asseverar que a concepção da "legalidade da natureza" dos físicos "não é nenhum fato, nenhum 'texto", o filósofo insiste: "isso é interpretação, não texto" ${ }^{38} \mathrm{E}$, nessa mesma direção, caracteriza a filologia, “em um sentido muito geral," como "poder decifrar fatos sem falsificá-los com interpretação". ${ }^{39}$ Seria possível então separar texto de interpretação? Parece-nos que não. Como, para Nietzsche, todo acontecer tem caráter interpretativo, é efetivamente impossível suprimir a interpretação da leitura de um texto ou de um fato, sejam essas noçôes consideradas em seu sentido estrito ou em seu sentido amplo. Contudo, como vimos, o conceito de interpretação não designa um procedimento homogêneo, mas uma multiplicidade de modos de interpretar que, de maneira geral, podem ser caracterizados como artes boas ou ruins de interpretação. Assim, a nosso ver, nas ocasiōes em que afirma que uma boa arte de leitura é aquela que não falsifica o texto com interpretaçôes, o filósofo não exige que se suprima toda interpretação, o que seria efetivamente impossível, mas apenas que se evite uma arte ruim de interpretação. Ao dizer que a "'legalidade da natureza' [...] não é nenhum fato, nenhum 'texto'", Nietzsche se refere a um determinado modo de interpretar, precisamente àquele dos físicos, ou seja, à "vossa interpretação e 'filologia' ruim", que faz parte das "artes-de-interpretação ruins". ${ }^{40}$ Os físicos não conseguem sequer estabelecer um texto ou um fato não porque interpretam - pois todos, inclusive Nietzsche, interpretam -, mas sim porque procedem segundo uma arte ruim de interpretação.

A filologia ruim, que se vale de uma arte ruim de interpretação, seria caracterizada por três infrações metodológicas principais. ${ }^{4 \mathrm{r}} \mathrm{A}$ primeira delas, indicada no parágrafo 17 de $O$ Andarilho e sua Sombra, consiste na violação das regras de estabelecimento do texto por falsificação, manipulação e corrupção; essa transgressão, designada como falta de probidade, prepara o texto para que ele se adapte a

interpretador não se imiscua, de alguma maneira, no interpretado.

38 Para além de Bem e Mal \$22, KSA 5.37, tradução de RRTF modificada.

39 O Anticristo $\$ 52$, KSA 6.233.

40 Para além de Bem e Mal $\$ 22$, KSA 5.37, tradução de RRTF modificada.

4I Essa é a posição de Wotling (2009, pp. 45-49). 
uma "explicação" previamente formulada. A segunda infração é a confusão entre texto e interpretação, que caracteriza a "falta de filologia": ao "texto original" se sobrepõe uma interpretação, que passa a ser considerada como texto, sob o qual desaparece, por fim, aquele "texto original"; essa falta é cometida, por exemplo, pelos físicos. ${ }^{42}$ Estreitamente vinculada às duas precedentes, a terceira infração, desqualificada como mentirosa e delirante, se faz notar na abordagem de um texto a partir de uma interpretação de alcance global previamente estabelecida, a qual termina por se sobrepor àquele texto; típica dessa última transgressão é a exegese cristã do texto bíblico. ${ }^{43}$ Mas seria possível evitar completamente essas infraçōes? De que maneira? Para tentar evitá-las, deve-se em primeiro lugar tomar consciência de que toda relação com um texto, em sentido estrito ou amplo, constitui necessariamente um procedimento interpretativo. Assim, mesmo que não seja possível separar texto e interpretação, afastar-se-á a ilusão de tomar a própria interpretação como um texto isento de interpretação, como fizeram os físicos ${ }^{44} \mathrm{e}$ os intérpretes da Revolução Francesa. ${ }^{45}$ É certo que, como vimos, Nietzsche critica frequentemente a arbitrariedade de determinadas interpretações ${ }^{46}$, a introjeção do próprio intérprete naquilo que interpreta ${ }^{47} \mathrm{e}$, de maneira geral, o acréscimo, por meio de interpretação, de algo exterior ao processo interpretado. ${ }^{48} \mathrm{E}$, com efeito, ao se tomar consciência de que é impossível deixar de interpretar e de que, mesmo quando se procura extrair sentido, interpretar consiste basicamente em introduzir sentido a partir de uma perspectiva determinada, então se pode, na medida do possível, procurar evitar ao máximo proceder de modo arbitrário e falsificador, adotando-se um procedimento metódico, guiado por cautela, paciência, atenção, desconfiança, lentidão, rigor moral e tudo o que prescreve Nietzsche nas passagens em que trata da arte de ler e interpretar bem.

42 Cf. Para além de Bem e Mal \$22, KsA 5.37.

43 Cf. Fragmento Póstumo 34 [48] de abril/junho de I885, KsA II.435. Ver ainda A gaia Ciência $\$ 357$, KSA 3.600, tradução de RRTF: "Considerar a natureza como se ela fosse uma prova da bondade e custódia de Deus; interpretar a história em honra de uma razão divina, como constante testemunho de uma ordenação ética do mundo com intenções finais éticas; interpretar as próprias vivências, como a interpretavam há bastante tempo homens devotos, como se tudo fosse providência, tudo fosse aviso, tudo fosse inventado e ajustado por amor da salvação da alma: isso agora passou, isso tem contra si a consciência, isso, para toda consciência mais refinada, passa por indecoroso, desonesto, por mentira, efeminamento, fraqueza, covardia - é por esse rigor, se é que é por alguma coisa, que somos justamente bons europeus e herdeiros da mais longa e mais corajosa autossuperação da Europa”.

44 Cf. Para além de Bem e Mal \$22, KSA 5.37.

45 Cf. Para além de Bem e Mal \$38, KsA 5.56.

46 Cf. Fragmento Póstumo I4 [I5I] da primavera de I888, KSA I3.333.

47 Cf. Para além de Bem e Mal \$38, KsA 5.56.

48 Cf. Para além de Bem e Mal \$ I7, KSA 5.3I, e Fragmento Póstumo 7 [60] do final de I886/ primavera de I887, KSA I2.3I5. 
Todavia, assim como a tomada de consciência do caráter perspectivístico da existência não implica a "superação" ou a supressão de tal caráter, a tomada de consciência da dimensão interpretativa de uma leitura ou interpretação não possibilita sua "superação" ou supressão. E, sendo todo interpretar perspectivístico e consistindo em introduzir sentido, parece-nos legítimo colocar em dúvida a possibilidade de uma leitura ou interpretação que, por mais consciente de seu caráter interpretativo e fundada em rigor metodológico que seja ela, resulte sem quaisquer arbitrariedades ${ }^{49}$ e falsificações. ${ }^{50}$ Antes, precisamente por sua constituição interpretativa e perspectivística, toda leitura ou interpretação implica, em maior ou menor medida, introdução de sentido, arbitrariedade e falsificação, ainda que tais implicações possam ser involuntárias e passar despercebidas. Assim, se há elementos constituintes das artes ruins de interpretação que não podem ser completamente suprimidos, então eles têm de estar presentes de alguma forma também nas artes boas de interpretação: portanto, no limite, não é possível efetuar uma distinção absoluta entre artes de interpretação boas, de um lado, e ruins, de outro.

Contudo, embora interpretações boas e ruins não se distingam sob certos aspectos, por exemplo, na medida em que todas comportam introdução de sentido por parte do interpretante no interpretado, arbitrariedade e falsificação, daí não se segue que não se possam estabelecer especificações entre elas. Com efeito, é possível notar diferenças mesmo naquela característica que, de um ponto de vista mais abstrato, havia sido considerada comum a todas as interpretações: a introdução de sentido, para continuarmos num exemplo já evocado, pode encerrar, dependendo do caso, uma arbitrariedade e uma falsificação mais ou menos conscientes, mais ou menos desavergonhadas. Se as interpretações são suscetíveis de ser observadas como homogêneas sob determinadas relaçôes e como heterogêneas sob outras, então, quando consideradas em função de seus aspectos distintos, elas admitem hierarquização. Por isso, a ideia de que as interpretações não podem ser absolutamente distintas, por compreenderem características que, vistas de certo ângulo e em certo nível de abstração, são comuns a todas elas, não implica a negação da possibilidade de hierarquizar essas interpretaçôes nem a admissão da equivalência

49 "O mundo não é para nós apenas um conjunto de relações sob uma medida? Tão logo falte essa medida arbitrária, nosso mundo se desfaz!” (Fragmento Póstumo II [36] da primavera/ outono de I88I, KSA 9.454). Se, como vimos acima, tudo o que há são "interpretações de mundo", se cada centro de forças constrói seu mundo a partir de sua perspectiva (Fragmento Póstumo I4 [184] da primavera de I888, KsA 13.37I) e se, por fim, "nosso mundo" encerra necessariamente uma "medida arbitrária", então as noções de interpretação e de perspectiva implicam a ideia de arbitrariedade.

50 Ao delimitar o significado da "interpretação em geral", Nietzsche se refere "ao violentar, ajustar, encurtar, deixar de lado, inflar, ficcionar, falsear e tudo o mais que pertence à essência de todo interpretar" (Genealogia da Moral, "Terceira dissertação", \$24, KSA 5.400, tradução de RRTF). É o próprio autor que destaca o termo "essência". 
de todas elas: não implica, em resumo, um relativismo radical, entendido como atribuição de igual valor a toda interpretação.

\section{0 mundo como vontade de potência: uma hipótese necessária}

A impossibilidade de distinguir de maneira absoluta artes boas e ruins de interpretação, já indicamos acima, tampouco tem por consequência o desprezo do rigor metódico, como se não importasse o modo pelo qual se formulam uma interpretação, uma hipótese e um ensaio. Ao contrário: em todo procedimento interpretativo, deve-se redobrar a atenção com o objetivo de minimizar, na medida do possível, determinados aspectos inerentes às interpretaçôes.

Assim, ao mesmo tempo que atribui à sua concepção de mundo como vontade de potência o estatuto de interpretação, de hipótese e de ensaio, Nietzsche toma o cuidado de explicitar reiteradamente o rigor metodológico com que julga proceder em sua formulação. Pois é com base em tal rigor que ele não só avalia a sua concepção de mundo como superior às demais como também apresenta a sua elaboração como necessária. De fato, se a leitura do parágrafo 22 de Para além de Bem e Mal nos mostra que Nietzsche toma a sua concepção de mundo não como apenas mais uma interpretação, mas como resultante de uma boa arte de interpretação, o que lhe permite estimá-la superior em relação às demais, a leitura do parágrafo 36 do mesmo livro, por sua vez, indica de modo exemplar que o autor apresenta a sua concepção de mundo não como uma hipótese e um ensaio precipitados $^{51}$ e incompletos ${ }^{52}$, tal como outros por ele criticados, mas como uma hipótese e um ensaio formulados com rigor metodológico, o que confere necessidade à sua elaboração.

Esse rigor repousa na "parcimônia de princípios", já evocada no parágrafo I3 de Para além de Bem e Mal..$^{33}$ No parágrafo 36 do mesmo livro ${ }^{54}$, a atenção a essa economia de princípios se revela em diversos momentos da argumentação: por exemplo, quando, após supor que "nada outro está 'dado' como real, a não ser nosso mundo de apetites e paixões" (grifo nosso), Nietzsche pergunta se "esse 'dado' não basta para, a partir de seu semelhante, entender o assim chamado mundo mecânico" (grifo do autor); ao afirmar que "esta é uma moral do método", a saber: "não admitir várias espécies de causalidade, enquanto o ensaio de bastar-se com uma única não tiver sido levado até seu limite extremo" (grifo

5I Cf. Para além de Bem e Mal\$ I92, KSA 5.II3.

52 Cf. Fragmento Póstumo I4 [I88] da primavera de I888, KSA I3.376.

53 KSA 5.28, tradução de RRTF.

54 KSA 5.54-55, tradução de RRTF. 
nosso); ao escrever: "é quanto basta, para termos de arriscar a hipótese, se por toda parte onde são reconhecidos 'efeitos' não é vontade que faz efeito sobre vontade" (grifo nosso); ao propor: "suposto, enfim, que desse certo explicar toda a nossa vida de impulsos como a conformação e ramificação de uma forma fundamental da vontade - ou seja, da vontade de potência" (grifo do autor); e, por fim, ao concluir o parágrafo com a proposição de que "o mundo [...] seria justamente 'vontade de potência', e nada além disso" (grifo nosso). Como se nota, a exigência de parcimônia de princípios deve resultar numa hipótese que se aplique ao maior número possível de fenômenos: e, com efeito, Nietzsche formula uma hipótese cujo alcance é o próprio mundo.

Ao concluir o parágrafo com a proposição de que "o mundo [...] seria justamente 'vontade de potência', e nada além disso", Nietzsche reitera, empregando o verbo no modo conjuntivo, o aspecto hipotético de sua concepção. É preciso notar, no entanto, que o filósofo atribui um caráter de necessidade - como atesta o emprego do verbo modal müssen - à formulação hipotética de pontos fundamentais da argumentação que resultará na concepção de mundo como vontade de potência: isso ocorre, por exemplo, na passagem em que assevera que "temos [müssen] de fazer o ensaio de pôr hipoteticamente a causalidade da vontade como a única"; e igualmente linhas abaixo, onde escreve: "é quanto basta, para termos $[$ muss $]$ de arriscar a hipótese, se por toda parte onde são reconhecidos 'efeitos' não é vontade que faz efeito sobre vontade". "5m suma: hipóteses, mas hipóteses necessárias.

O caráter necessário da formulação dessas hipóteses decorre, entretanto, da admissão de determinadas proposições, as quais, por seu turno, são apresentadas como suposições e até mesmo como crenças: "A pergunta é, por último, se reconhecemos efetivamente a vontade como eficiente, se acreditamos na causalidade da vontade: se o fazemos - e no fundo a crença nisso é justamente nossa crença na própria causalidade - temos de fazer o ensaio de pôr hipoteticamente a causalidade da vontade como a única" ${ }^{56}$ Precisemos que aquelas proposições, das quais Nietzsche retira hipóteses apresentadas como necessárias, não parecem usufruir do mesmo estatuto aos olhos do filósofo, levando-se em conta o conjunto de seus textos. Por um lado, algumas proposições poderiam ser consideradas como subscritas pela própria filosofia de Nietzsche, a saber: a suposição de que "não podemos descer ou subir a nenhuma outra 'realidade', a não ser precisamente a realidade de nossos impulsos", sendo possível pensar o chamado mundo mecânico "como uma pré-forma da vida"; da mesma maneira, a suposição de

55 Para além de Bem e Mal \$36, KSA 5.54-55, tradução de RRTF.

56 Ibid., KSA 5.55 . 
que seria possível "explicar toda a nossa vida de impulsos como a conformação e ramificação de uma forma fundamental da vontade — ou seja, da vontade de potência, como é minha proposição"s7; e, por fim, a suposição de que seria possível "reconduzir todas as funçôes orgânicas a essa vontade de potência" e de que nela residiria "a solução do problema da geração e nutrição".$^{8}$ Não seria fácil, porém, sustentar que a crença na causalidade, a qual é no fundo a crença na causalidade da vontade, desfruta igualmente do assentimento de Nietzsche: mesmo reconhecendo a utilidade prática da noção de causalidade, o filósofo não deixa de, com frequência, apontar seu caráter ilusório, que provém precisamente da crença na causalidade da vontade. E esse ponto não lhe passou despercebido durante a formulação do parágrafo 36 de Para além de Bem e Mal, como atesta o seguinte fragmento póstumo:

A pergunta é, por fim: se nós reconhecemos a vontade efetivamente como eficiente? Se nós a reconhecemos como tal, então naturalmente ela só pode fazer efeito sobre algo que é de sua espécie: e não sobre 'matéria'. $O u$ se deve considerar todo efeito como ilusão (pois nós nos formamos a representação de causa e efeito apenas segundo o modelo de nossa vontade como causa!) e então nada é de modo algum compreensível: ou se deve tentar pensar todo efeito como sendo de mesma espécie, como atos de vontade, portanto fazer a hipótese se todo acontecer mecânico, na medida em que contém uma força, é precisamente ato de vontade. ${ }^{59}$

Nietzsche afirma de fato que "um quantum de potência é caracterizado pelo efeito [Wirkung] que ele produz e ao qual ele resiste" e que a relação entre os quanta dinâmicos "consiste em seu 'efetivar-se' [Wirken]" uns sobre os outros. ${ }^{60}$ No entanto, nesses fragmentos póstumos, o filósofo não parece conceber o "efetivar-se" dos quanta de potência baseado em "nossa crença na causalidade" ${ }^{61}$, mas simplesmente em termos de "exercer [auszuüben] potência sobre todos os outros quanta de força”. ${ }^{62}$ Por que então, mesmo correndo o risco de evocar o tão criticado par causa e efeito e de associar o efetivar-se dos quanta de potência

57 "A vida, como a forma do ser que nos é mais conhecida, é especificamente uma vontade de acumulação de força: todos os processos da vida têm aí a sua alavanca [...] A vida, como um caso singular: daqui a hipótese sobre o caráter global da existência (Fragmento Póstumo I4 [82] da primavera de I888, KSA I3.262).”

58 Para além de Bem e Mal $\$$ 36, KSA 5.55, tradução de RRTF. Ver ainda Fragmentos Póstumos 36 [3I] de junho-julho de I885, KSA II.563, e I4 [I74] da primavera de I888, KSA I3.360.

59 Fragmento Póstumo 40 [37] de agosto/setembro de I885, KSA II.647.

60 Fragmento Póstumo I4 [79] da primavera de I888, KSA I3.258 e 259.

6I Para além de Bem e Mal $\$ 36$, KSA 5.55, tradução de RRTF.

62 Fragmento Póstumo I4 [8I] da primavera de I888, KSA I3.26I. 
à noção de causalidade, o filósofo admite no parágrafo 36 de Para além de Bem e Mal "nossa crença na causalidade" para então assegurar que "temos de fazer o ensaio de pôr hipoteticamente a causalidade da vontade como a única"?

Procedendo assim, Nietzsche lança mão de mais um meio para tentar evidenciar a superioridade de sua hipótese de mundo diante das outras, pois mesmo admitindo a crença na causalidade, a partir da qual se formam outras concepçōes de mundo, como a mecanicista, o filósofo chega necessariamente à formulação da hipótese da vontade de potência. Uma vez admitida a crença na causalidade ${ }^{63}$, torna-se então necessário fazer o ensaio de pôr hipoteticamente a causalidade da vontade como a única, o que conduzirá incontornavelmente à formulação das seguintes hipóteses: "se por toda parte onde são reconhecidos 'efeitos' não é vontade que faz efeito sobre vontade - e se todo acontecer mecânico, na medida em que uma força é ativa nele, não é justamente força de vontade, efeito de vontade" ${ }^{64}$; e a sequência da argumentação levará, por fim, à determinação de toda força eficiente e do próprio mundo como vontade de potência.

Aceitando o pressuposto do adversário, isto é, a crença na causalidade, Nietzsche faz ver que tal interlocutor não retira de sua própria premissa a consequência necessária, ou seja, a concepção do mundo como vontade de potência. Mas temos de precisar ainda que, embora conduza necessariamente à elaboração da hipótese segundo a qual o mundo seria vontade de potência, a crença na causalidade não desempenha o papel de uma condição sine qua non: em outros termos, aquela hipótese independe dessa crença, que é, de fato, amiúde criticada por Nietzsche. Assim, mesmo podendo formular a hipótese da vontade de potência sem supor a crença na causalidade, o filósofo a admite no contexto do parágrafo $36 \mathrm{com}$ o propósito de derrotar o adversário a partir do pressuposto do próprio adversário.

O caráter hipotético da concepção de mundo como vontade de potência é, portanto, complexo. Nietzsche coloca em sua base suposições de diferentes estatutos: algumas delas podem ser consideradas subscritas por sua própria filosofia, ao passo que a ideia de causalidade, apresentada como uma crença, não conta com o seu assentimento incondicional, tendo sido incorporada ao parágrafo 36 de Para além de Bem e Mal para nele desempenhar uma função específica. Mesmo que a crença na causalidade não constitua uma condição necessária para a elaboração da hipótese da vontade de potência, se tal crença for admitida, deve-se necessariamente formular a mencionada hipótese: desse modo, Nietzsche mostra que as concepções de mundo baseadas na crença na causalidade não extraem de

63 A crença na causalidade não é um artigo de fé qualquer, pois sem ela a espécie poderia perecer; assim, ela faz parte daquelas "admissões" denominadas "verdades" (Fragmento Póstumo 26 [I2] do verão/outono de I884, KSA II.I52-I53).

64 Para além de Bem e Mal $\$ 36$, KSA 5.55, tradução de RRTF. 
seu próprio pressuposto aquela consequência inevitável, ou seja, a elaboração da hipótese da vontade de potência. Já a admissão das outras suposições — isto é, das que consideramos proposições do próprio pensamento de Nietzsche - se mostra necessária para a elaboração da hipótese da vontade de potência: em outras palavras, não se trata apenas de dizer que da aceitação daquelas suposições decorre necessariamente a hipótese da vontade de potência, mas de dizer também que a inadmissão delas obstruiria a formulação dessa hipótese.

As consequências retiradas de determinadas proposiçóes, apresentadas como suposições, são necessárias do ponto de vista da formulação, mas ainda assim hipotéticas; e uma hipótese continua a ser uma interpretação, não uma explicação nem uma verdade absoluta. As últimas palavras do parágrafo 22 de Para além de Bem e Mal evidenciam que Nietzsche não recebe como uma acusação a atribuição de um estatuto interpretativo à sua concepção de mundo: "Posto que também isto seja somente interpretação", diz aos físicos, "- e sereis bastante zelosos para fazer essa objeção? — ora, tanto melhor!” ${ }^{65}$ Contrária seria a atitude de um dogmático, para quem a afirmação do caráter interpretativo de suas pretensas explicaçóes e verdades absolutas soaria como uma grave objeção. As últimas palavras do mencionado parágrafo mostram também que o fato de Nietzsche considerar sua concepção de mundo superior às demais, na medida em que resulta de uma boa arte de interpretação, não o conduz a pretender que ela seja mais do que uma interpretação: ao contrário, ela continua a ser "somente interpretação".

Do mesmo modo, a sequência do livro indica de maneira evidente que a atribuição de um caráter hipotético à concepção de mundo de Nietzsche não pode lhe soar como objeção, já que é ele próprio que, no parágrafo 36, reivindica com insistência tal estatuto. Com efeito, essa maneira de proceder encontra-se em consonância com uma postura mais geral de Nietzsche, a qual consiste não apenas em defender a ideia de que as pretensas verdades e explicaçôes não são mais do que hipóteses, mas também em deslegitimar a própria aspiração de transpor o domínio das conjecturas: " $\mathrm{Na}$ ciência as convicções não têm nenhum direito de cidadania [...]: somente quando elas se resolvem a rebaixar-se à modéstia de uma hipótese, de um ponto de vista provisório de ensaio, de uma ficção regulativa, pode ser-lhes concedida a entrada e até mesmo um certo valor dentro do reino do conhecimento". ${ }^{66}$ É em virtude dessa reserva que Nietzsche designa o mecanicismo, por exemplo, como hipótese ${ }^{67}$, interpretação ou descrição de mundo, mas não como uma explicação de mundo ${ }^{68} \mathrm{e}$ ainda menos como uma verdade absoluta.

65 Para além de Bem e Mal \$22, KSA 5.37, tradução de RRTF.

66 A gaia Ciência $\$$ 344, KSA 3.574, tradução de RRTF.

67 Cf. Fragmento Póstumo 34 [247] de abril/junho de I885, KSA II.504.

68 Cf. Para além de Bem e Mal \$ I4, KSA 5.28 e Fragmento Póstumo 36 [34] de junho/julho 
Tomar uma hipótese como hipótese é, para Nietzsche, um sinal de força e, portanto, de superioridade. "Considero todas as morais existentes até agora como construídas a partir de hipóteses sobre os meios de conservação de um tipo", afirma o filósofo em uma anotação póstuma, para em seguida advertir: "Mas a espécie de espírito existente até agora era ainda demasiadamente fraca e incerta de si mesma para captar uma hipótese como hipótese e, no entanto, tomá-la como reguladora - necessitou da crença". ${ }^{69}$ Em contrapartida, declara: "Até que ponto alguém é capaz de viver baseado em hipóteses, como navegando em mares abertos, em vez de 'crenças', eis a mais elevada medida de plenitude de força. Todos os espíritos inferiores perecem". ${ }^{70}$ Considerar um índice de plenitude de força a capacidade de reconhecer que se vive baseado em hipóteses não significa sugerir que as hipóteses têm o mesmo valor: aos olhos de Nietzsche, as hipóteses não se equivalem e devem ser julgadas também conforme o rigor de sua elaboração. Com efeito, ao designar uma determinada interpretação como hipotética, o filósofo frequentemente lhe confere um sentido depreciativo. Depois de afirmar que a noção de "sujeito" consiste numa "interpretação", em algo "inventado-a-mais", ele acrescenta: "Por fim, ainda é necessário pôr o intérprete atrás da interpretação? Isso já é invenção, hipótese". ${ }^{71}$ Nessa passagem, hipótese significa invenção e interpretação - ou melhor, para dizer de modo mais preciso e retomando o vocabulário do parágrafo 22 de Para além de Bem e Mal: trata-se de uma hipótese resultante de uma arte ruim de interpretação. Em outro texto, o parágrafo 192 do mesmo livro, Nietzsche afirma que no início de "todo 'saber e conhecer' [...] se desenvolveram primeiramente hipóteses precipitadas, invençôes, a boa e estúpida vontade de 'crença', a falta de desconfiança e paciência". ${ }^{72}$ Também nesse caso as hipóteses são desqualificadas e, poderíamos novamente dizer, associadas a artes ruins de interpretação. ${ }^{73}$ É por isso que, além de reconhecer o caráter hipotético de sua proposição, postura que aos seus olhos indica plenitude de força, Nietzsche se esforça também para proceder com rigor metodológico e assim elaborar uma hipótese que possa se pretender superior às demais.

de I885, KSA II.564-565.

69 Fragmento Póstumo 26 [263] do verão/outono de I884, KSA II.219.

70 Fragmento Póstumo 25 [515] da primavera de I884, KSA II.I48.

7I Fragmento Póstumo 7 [60] do final de I886/primavera de I887, KSA I2.315.

72 Para além de Bem e Mal \$ I92, KSA 5.II3.

73 Veja-se ainda a referência depreciativa de Nietzsche às hipóteses de Paul Rée (Genealogia da Moral, "Prefácio", \$ 4 e \$7, KSA 5.250-25I e 254). 


\section{Uma abordagem circular da circularidade}

A concepção de mundo como vontade de potência pode ser considerada superior não apenas porque resulta de uma boa arte de interpretação e porque consiste numa hipótese rigorosamente formulada, mas também na medida em que se trata de uma concepção de mundo passível de ser afirmada pelas estimativas de valor provenientes e fomentadoras de um modo de vida ascendente.

As concepções de mundo traduzem modos de estimar valores e, inversamente, os modos de estimar valores partilham de certos pressupostos presentes em determinadas concepçóes de mundo. Assim, a ideia de "legalidade da natureza" dos físicos é, para Nietzsche, "somente um arranjo ingenuamente humanitário e uma distorção de sentido, com que dais plena satisfação aos instintos democráticos de alma moderna! 'Por toda parte igualdade diante da lei — nisso a natureza não está de outro modo nem melhor do que nós': um maneiroso pensamento oculto, em que mais uma vez está disfarçada a plebeia hostilidade contra tudo o que é privilegiado e senhor de si $[\ldots]$ ". ${ }^{74}$ Ao satisfazer os instintos democráticos e ao pretender a igualdade por toda parte, uma concepção de mundo que propõe a "legalidade da natureza" traduz um modo de valorar que é hostil ao que é privilegiado e senhor de si.

Por outro lado, com "a intenção e a arte de interpretação opostas", Nietzsche se apresenta como um intérprete capaz de, "tendo em vista os mesmos fenômenos, decifrar precisamente a imposição tiranicamente irreverente e inexorável de reivindicações de potência", "a falta de exceção e a incondicionalidade que há em toda 'vontade de potência' ". 75 No domínio moral, essa concepção de mundo só pode ser afirmada por um modo senhorial de estimar valores, marcado não pela aspiração por igualdade, mas sim pelo "pathos da distância":

Foram antes "os bons", eles próprios, isto é, os nobres, poderosos, mais altamente situados e de altos sentimentos, que sentiram e puseram a si mesmos e a seu próprio fazer como bons, ou seja, de primeira ordem, por oposição a tudo o que é inferior, de sentimentos inferiores, comum e plebeu. Desse pathos da distância é que tomaram para si o direito de criar valores [...]. O pathos da nobreza e da distância, como foi dito, o duradouro e dominante sentimento global e fundamental de uma espécie superior de senhores, posta em proporção com uma espécie inferior, com um "abaixo" — essa é a origem da oposição "bom" e "ruim". ${ }^{76}$

No entanto, no âmbito da moral, aquela concepção de mundo apresentada

74 Para além de Bem e Mal \$22, KSA 5.37, tradução de RRTF.

75 Ibid.

76 Genealogia da Moral, "Primeira dissertação", $\$$ 2, KSA 5.259, tradução de RRTF modificada. 
por Nietzsche, segundo a qual "cada potência, a cada instante, tira sua última consequência" 77 , tem de ser negada pelo modo de atribuir valores proveniente de uma espécie fraca de homens, que "separa a força das exteriorizações da força, como se por trás do forte houvesse um substrato indiferente, ao qual fosse livre exteriorizar ou não a força". ${ }^{78}$ Conduzidos por um instinto de autoconservação e seduzidos pela gramática, os fracos postulam o sujeito como um substrato livre, separado e autor da ação; desse modo, eles, os fracos, podem responsabilizar os fortes por exteriorizarem sua força e ao mesmo tempo podem interpretar sua própria impotência e sua própria fraqueza como algo voluntário. Entretanto, adverte Nietzsche, "exigir da força que não se exteriorize como força, que ela não seja um querer-dominar, um querer-subjugar, um querer-assenhorear-se, uma aspiração por inimigos e resistências e triunfos, é tão absurdo quanto exigir da fraqueza que ela se exteriorize como força". ${ }^{79}$ É justamente a "medida de força" de uma época que determina, afirma Nietzsche ao dar a ver o seu "conceito de moderno", quais virtudes lhe são proibidas ou permitidas: ou uma época possui as virtudes da vida ascendente e resiste às virtudes da vida declinante, ou uma época, equivalendo a uma vida declinante, necessita das virtudes de declínio e "odeia tudo o que se justifica apenas a partir da plenitude, da abundância de forças" ${ }^{80} \mathrm{Na}$ esfera dos valores morais, a maior oposição se dá entre a moral cristã, que "nega o mundo" — “('Deus', 'além', 'abnegação', meras negaçōes)” —, e a moral dos senhores, que, sendo linguagem simbólica "da vida ascendente, da vontade de potência como princípio da vida", traduz uma afirmação do mundo ${ }^{81}$, precisamente do mundo como vontade de potência.

Assim, "o critério da verdade" estabelecido por Nietzsche - "A vontade de potência, como vontade de vida — de vida ascendente" ${ }^{\text {- }}$ — visa a distinguir as estimativas de valor provenientes e fomentadoras de uma espécie de vida ascendente daquelas provenientes e fomentadoras de uma espécie de vida decadente. ${ }^{83}$ Superior, o primeiro modo de estimar valores traduz a afirmação da concepção nietzschiana de vida e de mundo como vontade de potência, ao passo que o segundo, a sua negação. A concepção de mundo como vontade de potência, por

77 Para além de Bem e Mal \$22, KSA 5.37, tradução de RRTF.

78 Genealogia da Moral, "Primeira dissertação", \ I3, KSA 5.279.

79 Ibid.

8o O Caso Wagner, "Epílogo", Ksa 6.50.

8I O Caso Wagner, "Epílogo”, ksA 6.5I.

82 Fragmento Póstumo I6 [86] da primavera/verão de I888, KSA I3.5I6.

83 Sobre o tema do critério em Nietzsche, ver Marton, 2000, pp. 73-I00, e Marton, 20I4, pp. $205-226$. 
sua vez, é superior precisamente na medida em que é afirmável apenas por um modo de estimar valores proveniente de uma espécie de vida ascendente.

Mas, considerado desse modo, o pensamento de Nietzsche não incorreria em circularidade? Relevante, esse tema não escapou ao próprio filósofo, deixando-se ver, parece-nos, no parágrafo nono de Para além de Bem e Mal. Ali, ele dirige de início a seguinte afirmação aos estoicos: "Com todo seu amor pela verdade, vocês se forçam de modo tão duradouro, tão persistente, tão hipnoticamente inflexível a ver a natureza de modo falso, isto é, estoico, até que vocês não possam mais vê-la diferentemente [...]". Em seguida, porém, a crítica direcionada inicialmente de maneira específica aos estoicos é generalizada: "Mas esta é uma antiga, eterna história: o que então ocorreu com os estoicos ocorre ainda hoje, tão logo uma filosofia comece a acreditar em si própria. Ela sempre cria o mundo conforme a sua imagem, ela não pode fazer diferentemente; filosofia é esse impulso tirânico mesmo, a mais espiritual vontade de potência, de 'criação do mundo', de causa prima" ${ }^{84}$ Nessa passagem, Nietzsche atribui circularidade a toda filosofia ao afirmar que, "tão logo uma filosofia comece a acreditar em si própria", ela "sempre cria o mundo conforme a sua imagem". E o filósofo sugere que isso também se aplica a ele, na medida em que explica até mesmo o tema da circularidade à luz de sua própria concepção de mundo como vontade de potência: toda filosofia é circular, criando o mundo à sua própria imagem, porque toda filosofia é vontade de potência. Trata-se, dito de outro modo, de uma abordagem circular da circularidade.

A atribuição de circularidade soaria como objeção a Nietzsche? Assim como aquela pretensa acusação de que a concepção do mundo como vontade de potência seria "somente interpretação" não consiste efetivamente, aos olhos do autor, numa objeção; assim como, portanto, a sua filosofia reconhece o seu caráter interpretativo em vez de procurar dissimulá-lo - talvez seja igualmente legítimo dizer que, sem entender por isto uma objeção, a filosofia de Nietzsche também se reconheceria como circular em vez de tentar esconder certa circularidade que é, conforme indica o nono parágrafo de Para além de Bem e Mal, constitutiva de toda filosofia. A circularidade parece vinculada à constatação de que toda filosofia se encontra presa à sua perspectiva, à sua interpretação, à sua maneira de valorar, a partir das quais constrói o mundo - o seu mundo — e se julga superior.

Assim, circunscrito em sua perspectiva, Nietzsche é consequente ao reivindicar a superioridade de sua interpretação, de acordo com o critério por ela engendrado. Contudo, isso não significa que, para além da perspectiva do pensamento de Nietzsche, essa pretensão seja necessariamente legítima.

84 Para além de Bem e Mal \$9, KsA 5.22. 


\section{Referências}

Azevedo, V. D. Nietzsche e a aurora de uma nova ética. São Paulo: Humanitas; Ijuí: Unijuí, 2008.

Blondel, E. Nietzsche, le corps et la culture. La philosophie comme généalogie philologique. Paris: PUf, 1986.

ItAPARICA, A L. M.. "Relativismo e circularidade: a vontade de potência como interpretação". Cadernos Nietzsche, 27, pp. 239-253, 2010.

Lima, M. J. S. Perspectivismo e verdade em Nietzsche: da apropriação de Kant ao confronto com o relativismo. 20I0. $205 \mathrm{f}$. Tese (Doutorado em Filosofia). Faculdade de Filosofia, Letras e Ciências Humanas. Departamento de Filosofia, Universidade de São Paulo, São Paulo, 20 Io.

Marton, S. Nietzsche: das forças cósmicas aos valores humanos. Belo Horizonte: Editora UFMG, $2^{\text {a }}$ ed., 2000.

Marton, S. "Crepuisculo dos Ídolos: Em busca de um critério de avaliação das avaliações”. In: Marton, S. Nietzsche e a arte de decifrar enigmas - Treze conferências europeias. São Paulo: Edições Loyola, 2014.

MüLler-Lauter, W. "Nietzsches Lehre vom Willen zur Macht". Nietzsche-Studien, 3, pp. I-60, 1974 .

Nasser, E. Nietzsche e a ontologia do vir-a-ser. São Paulo: Edições Loyola, 2015.

Nietzsche, F. Werke. Kritische Gesamtausgabe in 33 Bänden [KGw]. Giorgio Colli e Mazzino Montinari (Org.). Berlim e Nova York: Walter de Gruyter, 1963 e seq.

Nietzsche, F. Sämtliche Werke. Kritische Studienausgabe [кsa]. Giorgio Colli e Mazzino Montinari (Org.). Munique: Walter de Gruyter, I999.

Nietzsche, F. Friedrich Nietzsche: Obras incompletas. Trad. Rubens Rodrigues Torres Filho. São Paulo: Editora Nova Cultural, 2000.

Silva Jr., I. da. "Nietzsche, entre a arte de ler bem e seus leitores". Cadernos Nietzsche, 35, pp. 17-31, 2014.

Wotling, P. Nietzsche et le problème de la civilisation. Paris: PUf, 2009. Em português: Wotling, P. Nietzsche e o problema da civilização. (Col. Sendas \& Veredas), São Paulo: Barcarolla, 2013. 